\title{
DETECCIÓN DE MÉDANOS Y FOCOS DE EROSIÓN COMO INDICA- DORES DE AMBIENTES SUSCEPTIBLES A LA REACTIVACIÓN DE PROCESOS DE EROSIÓN EÓLICA Y DESERTIFICACIÓN
}

\author{
Catalina Bozzer ${ }^{1}$ y José Manuel Cisneros ${ }^{2}$
}

1- Departamentos de Ecología Agraria y Uso y Manejo de Suelos. Facultad de Agronomía y Veterinaria. Universidad Nacional de Río Cuarto. Consejo Nacional de Investigaciones Científicas y Técnicas, Argentina.

2- Profesor Titular Uso y Manejo de Suelos. Departamento de Ecología Agraria. Facultad de Agronomía y Veterinaria. Universidad Nacional de Río Cuarto.

Palabras Clave

semi-árido

geoformas

digitalización
Resumen. La Pampa Medanosa es la región de la provincia de Córdoba con mayor susceptibilidad a la erosión eólica. En los últimos años, ha sido reportada en ella la reactivación de procesos erosivos a causa de la deforestación y de la intensificación del uso de la tierra. El objetivo de este estudio fue, por un lado, realizar la digitalización de las geoformas medanosas para dar información de base a la identificación de áreas de protección/conservación. Y, por otro lado, a través de la digitalización los focos de erosión, identificar áreas con reactivación de procesos eólicos. Se digitalizaron 66.448 hectáreas de focos de erosión evidenciando la acción de la erosión eólica en el suroeste de la provincia de Córdoba y 73.672 hectáreas de geoformas medanosas permitiendo la localización espacial de ambientes con requerimientos de protección/conservación atendiendo el fraccionamiento del corredor biogeográfico del Caldenal y de las geoformas mismas por el avance del uso agrícola. La presencia de focos de erosión activos señala la necesidad de la planificación del uso y manejo de la tierra con una visión a largo plazo, a los fines de rehabilitar las tierras degradadas y evitar el avance hacia la desertificación.
Citar como: Bozzer, C. y Cisneros J.M. (2019) Detección de médanos y focos de erosión como indicadores de ambientes susceptibles a la reactivación de procesos de erosión eólica y desertificación.. Revista Científica FAV-UNRC $A b$ Intus 4 (2): 01-13

Recibido: 28/05/19 Aceptado: 10/09/19

*Autor para correspondencia: Catalina Bozzer, Ruta Nacional N³6 Km 601, Río Cuarto, Córdoba, Argentina. CP 5800. Tel. (0358) 4676409 bozzercatalina@gmail.com 


\title{
Detection of dunes and erosion focus as indicators of susceptible envi- ronments to the reactivation of wind erosion processes and desertifica- tion
}

Key Words

semi-arid

geoforms

digitalization

\begin{abstract}
The Pampa Medanosa Region is the Córdoba province's environment with the greatest wind erosion susceptibility. In recent years, the reactivation of erosive processes in the region due to deforestation and intensification of land use has been reported. The aim of this work was to, on the one hand, to carry out the digitalization of dunes, to provide information for the identification of protection/conservation areas. And, on the other hand, through the digitalization of erosion foci, it was to observe the reactivation of wind erosion processes. 66,448 hectares of erosion foci were digitalized, showing the wind erosion consequences in the southwest of the province of Córdoba. Besides, 73,672 hectares of dunes were digitalized. The spatial location of them indicates fragile environments that require protection and conservation approaches, attending the breaking-up of the biogeographic Caldenal corridor and megadunes by agricultural land use. The presence of active wind erosion processes shows the need of land use planning and sustainable soil management in a long-term vision system, in order to rehabilitate degraded lands and to prevent desertification processes progress.
\end{abstract}

\section{Introducción}

Las Naciones Unidas han definido desertificación como un "...proceso complejo que reduce la productividad y el valor de los recursos naturales en el contexto específico de condiciones climáticas áridas, semiáridas y subhúmedas secas, como resultado de variaciones climáticas y de acciones humanas adversas" (UNCED, 1992; UNCCD, 1994). Este proceso ocurre cuando el hombre genera transformaciones en el territorio de la tal magnitud que la capacidad regenerativa del ecosistema se ve superada (Valderrama, 2017). La República Argentina es el país de América Latina con mayor superficie bajo las condiciones climáticas anteriormente mencionadas (75 $\%$ del territorio nacional). Sin embargo, estos ambientes producen el $50 \%$ del valor de la producción agrícola total nacional y el $47 \%$ de la ganadera; y concentran casi el $30 \%$ de la población nacional ( 9 millones de personas). Según datos del Programa de Acción Nacional de Lucha contra la Desertificación [PAN], de los 276 millones de hectáreas que com- ponen el territorio continental nacional, 60 millones están afectadas por distintos procesos y grados de desertificación y degradación de suelos, cuyos incrementos se estiman en 650.000 hectáreas por año (Pérez Pardo, 2005).

Los procesos que de alguna manera provocan en forma real o potencial una disminución de la capacidad productiva del suelo se denominan procesos de degradación, de ellos, uno de los más importantes, es la erosión, tanto hídrica como eólica (FAO-Unesco, 1975). La erosión eólica es uno de los principales desencadenantes de la desertificación. Según Casas (2015), en la República Argentina se registran 41 millones de hectáreas con erosión eólica, mientras que, para la provincia de Córdoba, Cisneros et al. (2015) reportaron 3,3 millones de hectáreas afectadas y un incremento del $74 \%$ en la superficie con un grado alto de afección respecto a lo registrado por Marelli (1996). El sector de la provincia con mayor grado de afección se ubica hacia el SO de la misma 
(Cisneros et al., 2015) y coincide geográficamente con la región de la Pampa Medanosa Cordobesa. Tripaldi et al. (2010) y Becher Quinodóz (2014) han mencionado la reactivación de médanos en esta zona como consecuencia de la deforestación y de la intensificación de uso de la tierra en la región.

Por otro lado, si bien existen mapas actuales para la provincia de Córdoba de la susceptibilidad a la erosión eólica (Cisneros et al., 2015) y de su geomorfología (Carignano et al., 2014), no existen antecedentes relativamente actuales de trabajos específicos en cartografía de los médanos para la Pampa Medanosa.

En vista de todo ello, se pretende contribuir al ordenamiento territorial de los ecosistemas frágiles de esta región mediante la identificación, localización y dimensionamiento de tierras que han sufrido o están sufriendo procesos de desertificación por erosión eólica mediante la identificación de focos de erosión y la localización de médanos, entendiéndose estos últimos como el resultado de procesos avanzados de erosión. La selección tanto de las geoformas medanosas como de los focos de erosión para actuar como indicadores se ejerció en vista de que cumplen las pautas sugeridas por Abraham y Salomón (2006), dentro de ellas, se destaca que son conocidos y significativos para diferentes tipos actores sociales, tienen relevancia política, son importantes para los funcionarios gubernamentales que tratan aspectos ambientales, y atienden la relación costo-eficacia ya que la selección de indicadores implica un compromiso convenido entre la precisión de la información, el tiempo y el equipamiento requeridos o disponibles, y la representatividad de los datos reunidos.

La cartografía de los indicadores seleccionados será de utilidad como información de base para la planificación del uso y del manejo de las tierras; en el marco de la Agenda 2030, podrá ser utilizada para contribuir a la lucha contra la desertificación, la rehabilitación de tierras y suelos degradados (Naciones Unidas, 2015).

Los indicadores son herramientas que traducen sintéticamente información acerca del estado y la tendencia de los sucesos ambientales (Rubio y Bochet, 1998). Huaico Malhue et al. (2018) en su revisión sobre la evolución de enfoques de desertificación, encontraron que un $57 \%$ de los autores estudiados implementó indicadores biofísicos para evaluar el avance de procesos ambientales degradativos. Estos indicadores integran elementos del paisaje y elementos biológicos, como las coberturas vegetales, con indicadores físicos, como la geomorfología. Siendo el elemento más usado dentro de la geomorfología el relieve. Según estos autores, indicadores económicos como el tipo de uso de la tierra, cuya incorporación es posible mediante la utilización de imágenes de satélite, son significativos para evaluar el estado y la presión ejercida sobre el recurso suelo; y a su vez, se adaptan al trabajo en grandes escalas. $Y$, en vista de que la desertificación es la materialización de la ruptura del equilibrio dentro de un sistema en el que interactúan los recursos naturales, la sociedad y las políticas económicas, es fundamental tener presente la participación de factores socioeconómicos para entender el inicio de los procesos de degradación y lograr su prevención. Principalmente en los ecosistemas áridos y semi-áridos, vulnerables a la explotación excesiva, inapropiados usos de la tierra y al cambio climático donde este enfoque preventivo es esencial para asegurar la productividad a largo plazo (Huaico Malhue et al., 2018).

Dado lo anteriormente expuesto, se propusieron para el presente trabajo como indicadores de ambientes susceptibles a la reactivación de procesos de erosión eólica y de desertificación dos elementos: formaciones medanosas y focos de erosión, respectivamente. Ambos contemplan aspectos biofísicos y de múltiples maneras se relacionan directamente con el uso actual de la tierra, principalmente los focos de erosión. Mientras que las geoformas medanosas, aunque durante la génesis de la mayoría de ellas no hubo participación antrópica (Instituto de Suelos y Agrotecnia, 1948), son un claro indicador de la fragilidad ecológica de los ambientes.

Por otra parte, los elementos seleccionados como indicadores han sido utilizados a nivel nacional (Abraham y Salomón, 2006) y están ampliamente difundidos tanto entre los productores como entre los actores políticos locales. Quienes conocen e identifican a las dunas o geoformas medanosas con el nombre de médanos y a los focos de erosión con el nombre de voladuras, en las que también inclu- 
yen los pequeños cúmulos de arenas, denominados frecuentemente acumulaciones de guadal. Se destaca que la información generada con la realización de este trabajo está en un lenguaje perfectamente comprensible para los tomadores de decisiones del medio rural en estudio siendo de gran utilidad no solo para los productores, sino también como información de base para la construcción de proyectos de conservación y de prevención de la degradación de los suelos en el marco de la Ley provincial para la Conservación y la Prevención de Degradación de los Suelos (Ley provincial N 8936, 2001).

Se pretende entonces, a través de la digitalización de las geoformas medanosas dar información de base para la generación de áreas de protección/conservación. Y, por otro lado, a través de la digitalización de los focos de erosión; dimensionar y ubicar espacialmente la reactivación de procesos eólicos y de desertificación en el área medanosa de la provincia de Córdoba.

\section{Materiales y métodos}

Área de estudio

La Pampa Medanosa se localiza sobre el suroes-

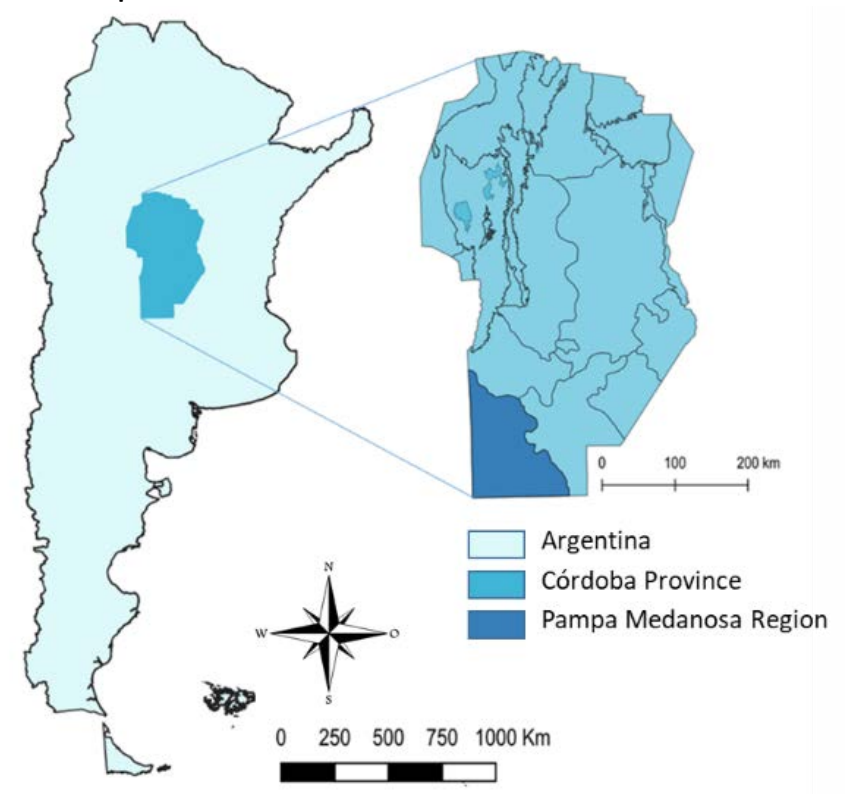

Figura 1. Regiones Naturales de la Provincia de Córdoba. Adaptado de Cabido et al. (2003).

te de la provincia de Córdoba comprende más de 1.400.000 hectáreas, ocupando casi por completo el departamento General Roca y el sector sur del departamento Río Cuarto (Figura 1). El área de estudio representa el 8,6\% de la superficie de la provincia, limita al este con la región de la Pampa Arenosa Anegable, al noroeste con la Pampa Arenosa Alta.

Es un ambiente ecológicamente frágil con susceptibilidad natural a los procesos de degradación por erosión eólica (Jarsún et al., 2006). La génesis de sus suelos se produjo sobre depósitos eólicos pleistocenos y holocenos, agrupados por Iriondo y Kröhling (1995) en una gran unidad geomorfológica denominada Sistema Eólico Pampeano [SEP]. Estos sedimentos presentan dos orígenes: por un lado, la intensa actividad volcánica de fines del Terciario y del Cuaternario en la zona cordillerana andina y en la provincia de Córdoba, y por otro, la acción eólica sobre las Sierras Pampeanas. El clima de la región es templado semiárido, resultante de diversos factores, principalmente de índole geográfica (Cantero et al., 1998; Jarsún et al., 2006).

\section{Determinación de categorías}

Para la generación de los mapas digitales se establecieron los siguientes elementos a cartografiar. Por un lado, médanos: geoformas representadas por acumulaciones de material erosionado bien definidas; y, por otro lado, focos de erosión eólica: sitios donde los procesos de degradación erosivos están comenzando o reactivándose. Estos últimos, son estadios intermedios que comprenden campos volados, desaparición del tapiz vegetal, alteraciones de la superficie por acumulaciones incipientes de arenas, playas voladas. Situaciones nominadas voladeras en el informe técnico "La erosión eólica en la Región Pampeana y Plan para la Conservación de los suelos" del Instituto de Suelos y Agrotecnia (1948).

La escala de trabajo propuesta fue de 1:25.000, en pos de lograr una cartografía de utilidad para la planificación del uso de la tierra. El área total de trabajo comprendió aproximadamente 1.400 .000 hectáreas. La identificación y digitalización de ambas situaciones se realizó mediante el análisis visual de imágenes satelitales provistas por las plataformas de Google Maps (Google Maps, 2018) y Bing Maps (Microsoft, 2018). Se empleó la red hidrográfica de Masciángelo (2014). La digitalización fue llevada a cabo utilizando la elevación provista por Google Earth Pro, los complementos Open Layers Plugin y Quick Map Services mediante el Software de uso libre Q Gis v2.14.3 Essen y v3. 4.6 Madeira (QGIS De- 
velopment Team, 2019).

Para la determinación tanto de las geoformas medanosas como de los focos de erosión se tuvieron en cuenta tres sub sets de indicadores visuales. En primer lugar, del tipo físicos, como material suelto desplazado, acumulado o removilizado por el viento, el albedo de la superficie, la forma del relieve, la altitud y la formación de cubetas de deflación. En segundo lugar, del tipo biológicos representados por la presencia o ausencia y el tipo de coberturas vegetales. Y, en tercer lugar, un factor económico, representado por el uso de la tierra.

Los médanos fueron identificados como geoformas bien definidas, vivos, fijados o parcialmente fijados, con vegetación natural o implantada. Se delimitaron percibiendo cambios en la vegetación, en el material superficial, en la coloración y el albedo de la superficie, en los manejos y usos asignados a la unidad. También se los localizó gracias a la presencia de cubetas de deflación, ocupadas con lagunas o no. Como herramienta complementaria se utilizó Google Earth Pro (2018) que permitió extraer perfiles de elevación para contemplar la variable altitud.

Para la digitalización de los focos de erosión, que aún no presentan formas definidas o lo hacen parcialmente, se tomaron características de la superficie como activa remoción del material superficial, disminución de las coberturas o ausencia de las mismas, zonas claras de gran albedo, arenas visibles removilizadas, desplazamiento de materiales en dirección al rumbo de los vientos.

\section{Resultados y discusión}

\section{Geoformas medanosas}

Se logró la construcción de un mapa de geoformas medanosas y otro de focos de erosión eólica de la Pampa Medanosa Cordobesa, ambos en escala 1:25.000.
La superficie total correspondiente a geoformas medanosas identificadas en la Pampa Medanosa Cordobesa fue de 73.671,6 hectáreas, las que representan aproximadamente el $5 \%$ superficie total de la región. Se visualizan dos zonas de concentración de los médanos bien definidas y con características diferentes; una al norte del Río Popopis y otra al sur y oeste del mismo (Figura 2). En concordancia con lo expuesto por Carignano et al. (2014).

En lo que respecta a la dirección de formación de los médanos, se identificaron dos tendencias contrastantes, claramente visibles, separadas por una zona de transición. Principalmente al norte del río Quinto, las geoformas siguen direcciones de deposición NNE-SSO (Figura 2); mientras que las geoformas del SO de la región son de mayor tamaño, fraccionadas, disipadas y menos perceptibles, y expresan una dirección de formación SSE-NNO. Empero, observándose una sobre imposición de formaciones más recientes, de dirección NNE-SSO, sobre las anteriores. Este fenómeno de sobreimposición de geoformas ocurre desde la localidad de Villa Valeria $\left(30^{\circ} 20^{\prime} 29,35^{\prime \prime}\right.$ Latitud Sur) hacia el sur. Evidenciando no solo la ocurrencia de más de un ciclo de deposición de sedimentos eólicos, sino también que los vientos durante estos ciclos tuvieron direcciones predominantes diferentes. Estas observaciones coinciden con las de Carignano et al. (2014) quienes mencionan para la provincia de Córdoba un escenario con ciclos secos y vientos fuertes provenientes del sur durante finales del Pleistoceno y comienzos del Holoceno (entre ca. 30 ka y ca. 9 ka.) en el que se depositó el manto de loess (planicie fluvioeólica central) y se formaron los mantos y campos de dunas (planicie eólica arenosa del sur) que condicionan la actual morfología de las llanuras. Y otro escenario más tardío, perteneciente al Holoceno (entre ca. 3 ka y ca. 1 ka.) que replica el escenario anterior, empero con un cambio en la dirección predominante de los vientos, esta vez provenientes del NE y en el que se erosionan geoformas y removilizan materiales hasta alcanzar el Optimum Climaticum. 


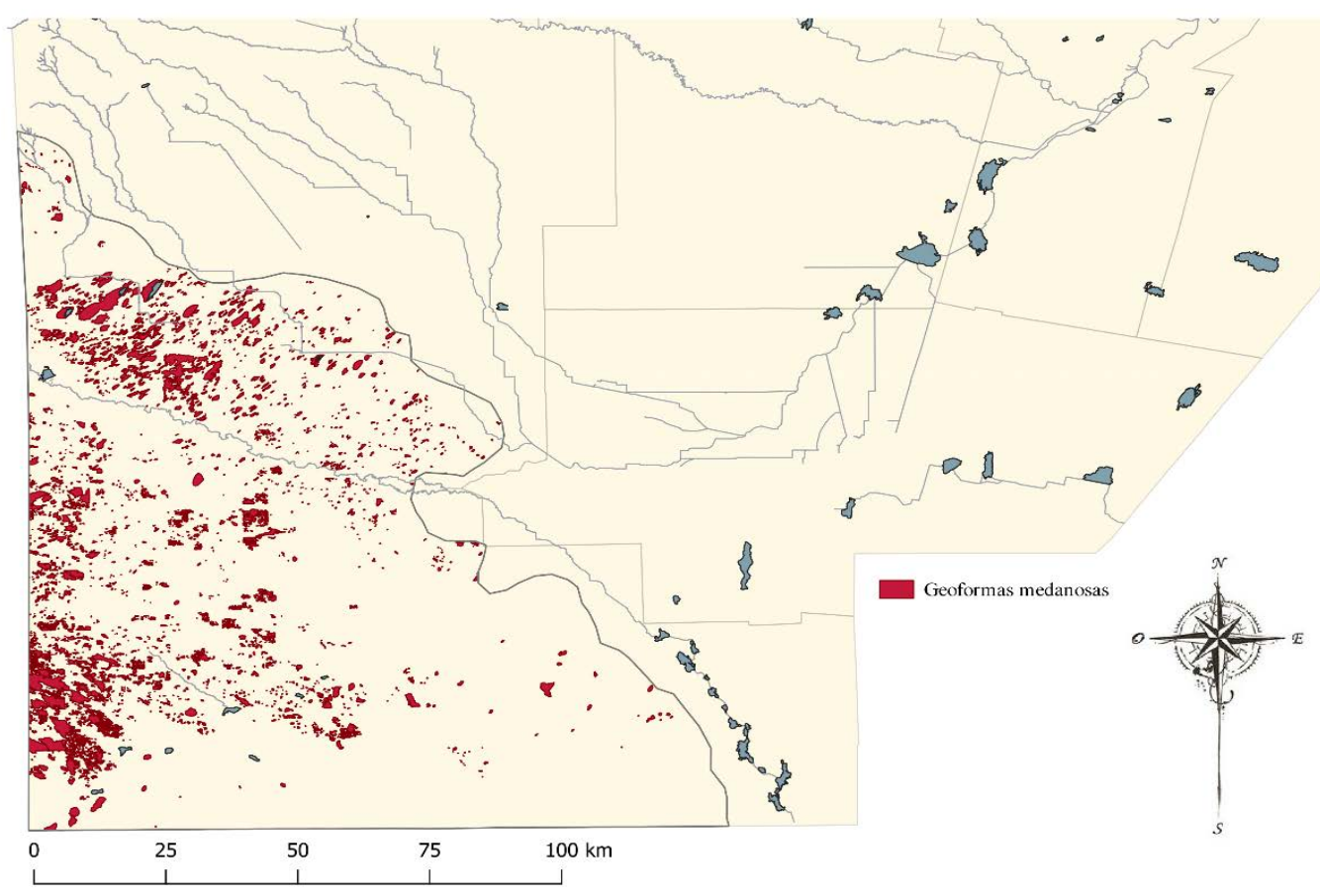

Figura 2. Digitalización de Geoformas medanosas de la Pampa Medanosa Cordobesa. La superficie total ocupada por las geoformas es de 73.671,6 hectáreas. Se visualizan dos zonas de concentración de médanos diferenciadas por su dirección de formación: una hacia norte del Río Popopis de tipo parabólicas y dirección NNE-SSO; y otra al sur y oeste de la región, fraccionadas y de mayor tamaño, con dirección SSE-NNO. El mapa se encuentra disponible a escala 1:25.000.

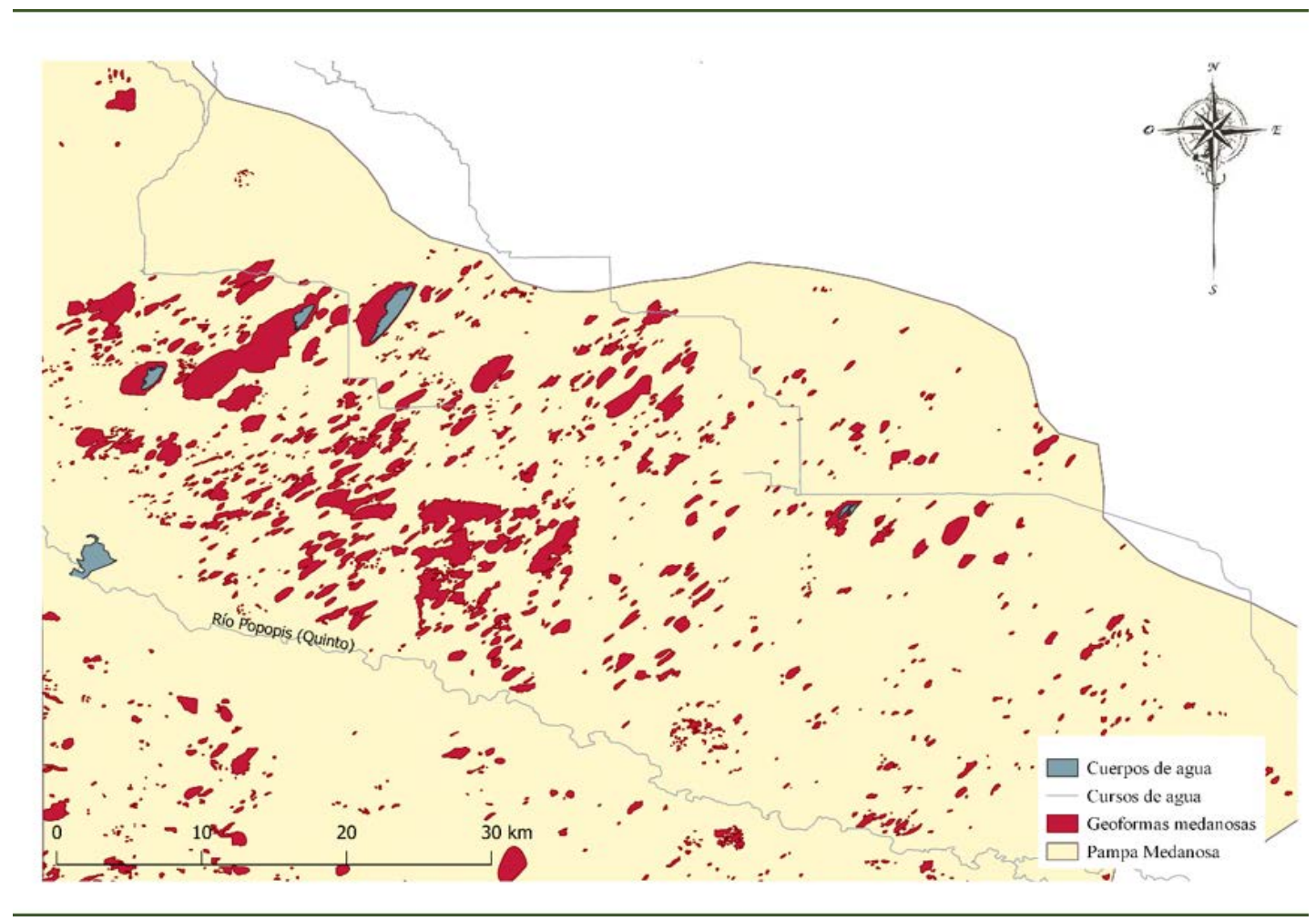

Figura 3. Formaciones medanosas sobre el norte del río Popopis (Quinto). Estas son las más jóvenes de la región, de tipo parabólicas con sus cubetas de deflación en el sector NNE indicando el sentido predominante de los vientos durante su formación. 
Los médanos ubicados hacia el norte del río Quinto (Figura 3), pertenecen a formación Laguna Oscura definida por Cantú (1992) y se encuentran dentro del campo de dunas de Laguna Oscura definido por Carignano et al. (2014). Son las más recientes en cuanto a su formación. Se desarrollaron durante la "pequeña edad de hielo" (PEH), período de enfriamiento y sequía que coincidió aproximadamente con el período colonial americano, y que en la Argentina produjo avances de glaciares en la Cordillera de los Andes y aridez en las tierras bajas (Cantú y Degiovanni, 1984). Iriondo (2010) menciona una re-movilización de arena eólica durante la $\mathrm{PEH}$ en un área de unos $1.500 \mathrm{~km}^{2}$ en la que se hallan las localidades de General Paunero y Washington.

Este sector, exhibe dunas parabólicas de diferentes tamaños que deben su origen a vientos de dirección NNE-SSO, presentan formas definidas, en gran medida asociadas a cubetas de deflación en el sector
ENE, áreas cóncavas con lagunas permanentes y semipermanentes (Blarasin y Sánchez, 1987) (Figura 4). Las dunas que lo componen son de distintas edades, algunas de ellas de origen antrópico y otras, la mayoría de ellas y las de mayor extensión, son más antiguas a la instalación de los primeros colonos (Instituto de Suelos y Agrotecnia, 1948; Cantú, 1992).

En este sector, se destaca la presencia de médanos parcialmente o total fijados con vegetación espontánea e implantados con árboles o cañaverales. El Instituto de Suelos y Agrotecnia (1948) menciona la fijación de estos médanos durante años próximos la gran sequía de 1937 con Caña de Castilla (Arundo donax L.) y hace referencia a las dificultades encontradas durante la construcción de los caminos y rutas por las acumulaciones de arenas y la formación de médanos (Figura 5).

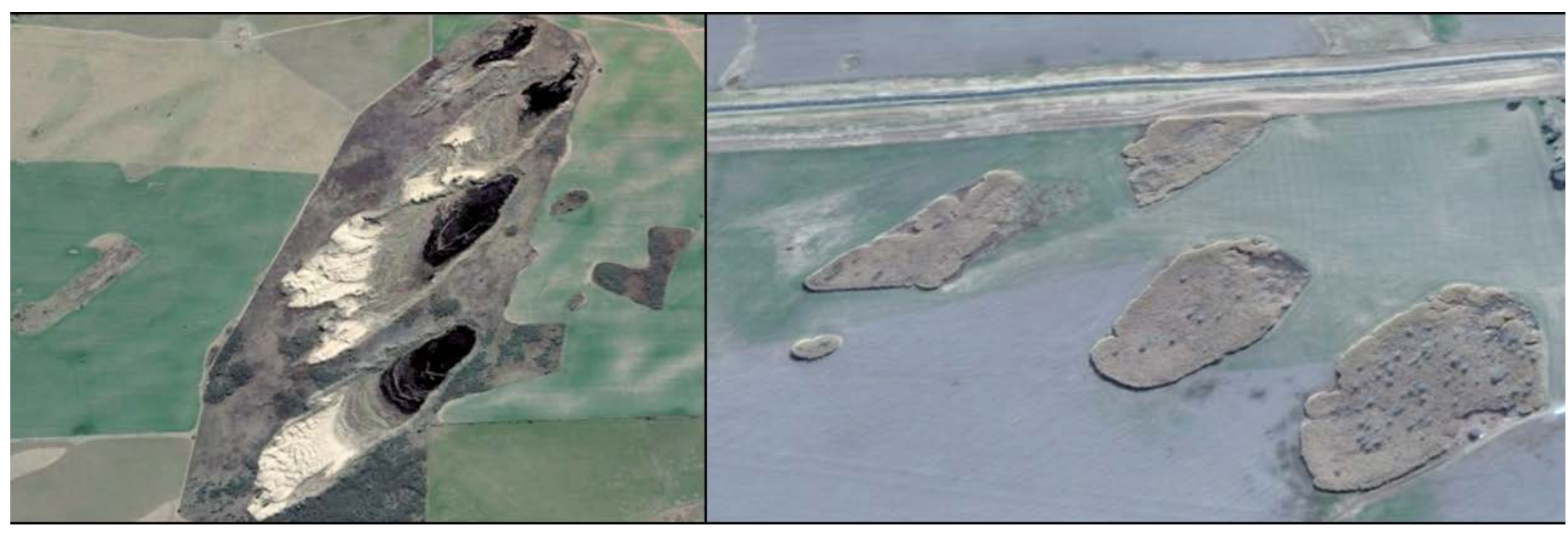

Figura 4 (Izquierda). Dunas parabólicas activas, de dirección NNE-SSO al norte de la Laguna Oscura (Google Erth Pro, Digital Globe, 2018). Figura 5 (derecha). Vista de imágenes satelitales de médanos fijados con Arundo donax L. al sur de General Paunero, sobre la Ruta Nacional N7 (Google Erth Pro, Digital Globe, 2018).

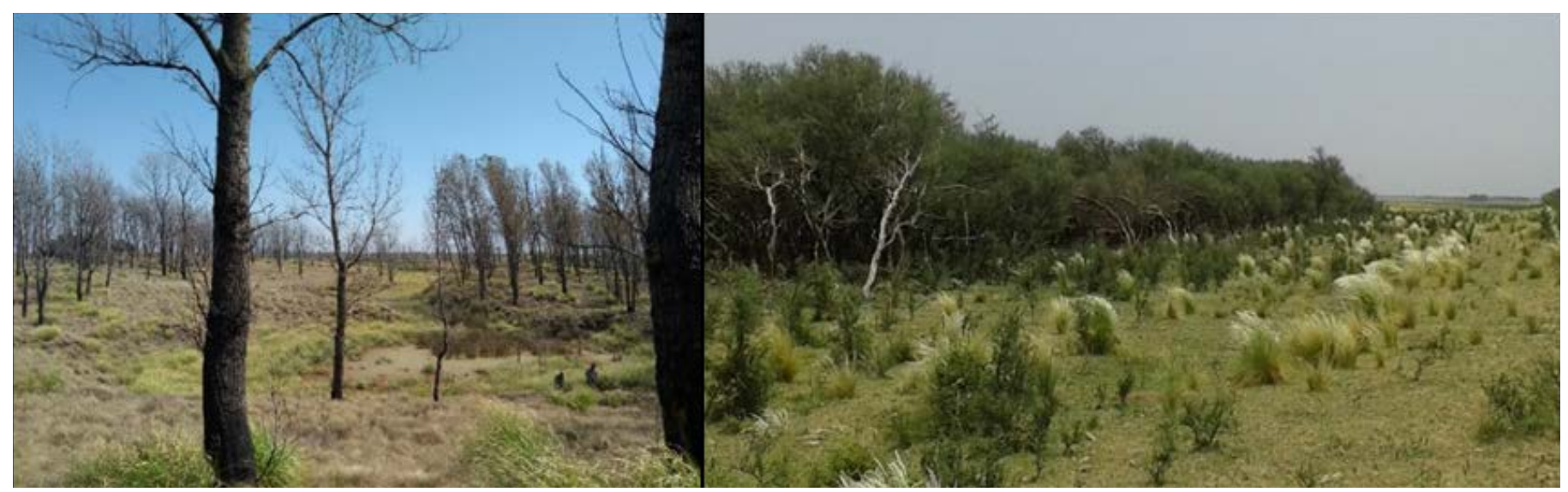

Figura 6 (Izquierda). Médanos fijados con pastizales y álamos sobre la Ruta Nacional N 7, su cubeta de deflación presenta una laguna semipermanente. Figura 7 (Derecha). Relicto de monte nativo, "chañaral", al norte de la localidad de Villa Huidobro. 
Hacia el sur del río Quinto la dirección de formación predominante es SSE-NNO, lo que indica que se formaron en un tiempo geológico anterior, en el que los vientos tuvieron una dirección diferente. Zárate y Tripaldi (2012) describen en el sur de San Luis dunas longitudinales (de hasta $25 \mathrm{~km}$ de longitud), y sugieren un origen por vientos provenientes del sudeste. Ramonell et al. (1992) que deducen una edad pleistocena tardía para las dunas longitudinales y Holoceno tardío para algunos de los campos de dunas sobre impuestos de San Luis. En el campo de dunas de Villa Valeria se observa claramente la sobreimposición a la que refiere Ramonell (op. cit.) (Figura 13).
Tripaldi y Forman (2007) y Latrubesse y Ramonell (2010) obtuvieron edades de estos campos de dunas en el sudeste de San Luis, por medio dataciones utilizando el método OLS (Optically Stimulated Luminescence dating), los primeros autores determinaron que corresponden al Último Máximo Glacial, mientras que para la secuencia de Laguna Oscura alcanzaron edades inferiores.

En pos de lo expuesto, los médanos no tienen una componente antrópica en su formación. Aunque la reactivación de la movilización de materiales en médanos agriculturizados sí corresponde a procesos de degradación desencadenados por el ser humano yes un indicador del inicio de procesos de desertificación.

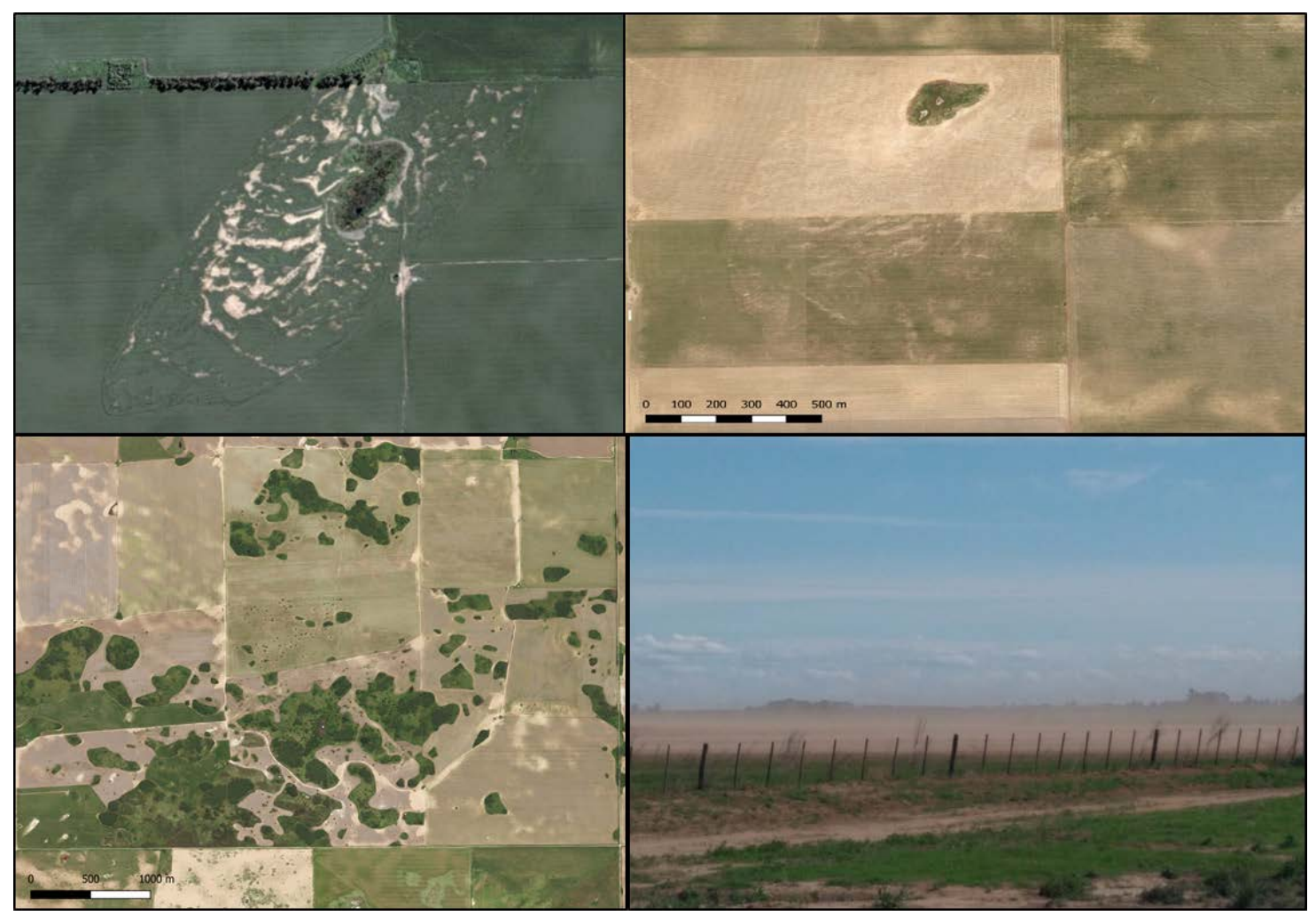

Figura 8. Médano bajo uso agrícola, con reactivación de procesos erosivos (Google Earth Pro, Digital Globe, 2018). Figura 9. Médano bajo uso agrícola al norte de la localidad de Nicolás Bruzzone, con reactivación de procesos erosivos (Bing Maps, 2019). Figura 10. Fraccionamiento de las geoformas medanosas por el uso agrícola de las y deforestación. Figura 11 (Derecha abajo). Campo volando en cercanías de la localidad de Ranqueles, sobre la ruta provincial $N^{\circ} 26$. 
Al sur de la región, el fraccionamiento por el uso agrícola de las geoformas medanosas y la deforestación es evidente. Aquellas que no han sido agriculturizadas, se conservan fijadas por monte nativo y pastizales naturales. La presencia de zonas de activa deflación es menor que hacia el norte, exhibiendo mayor estabilidad (Figuras 13 y 14).

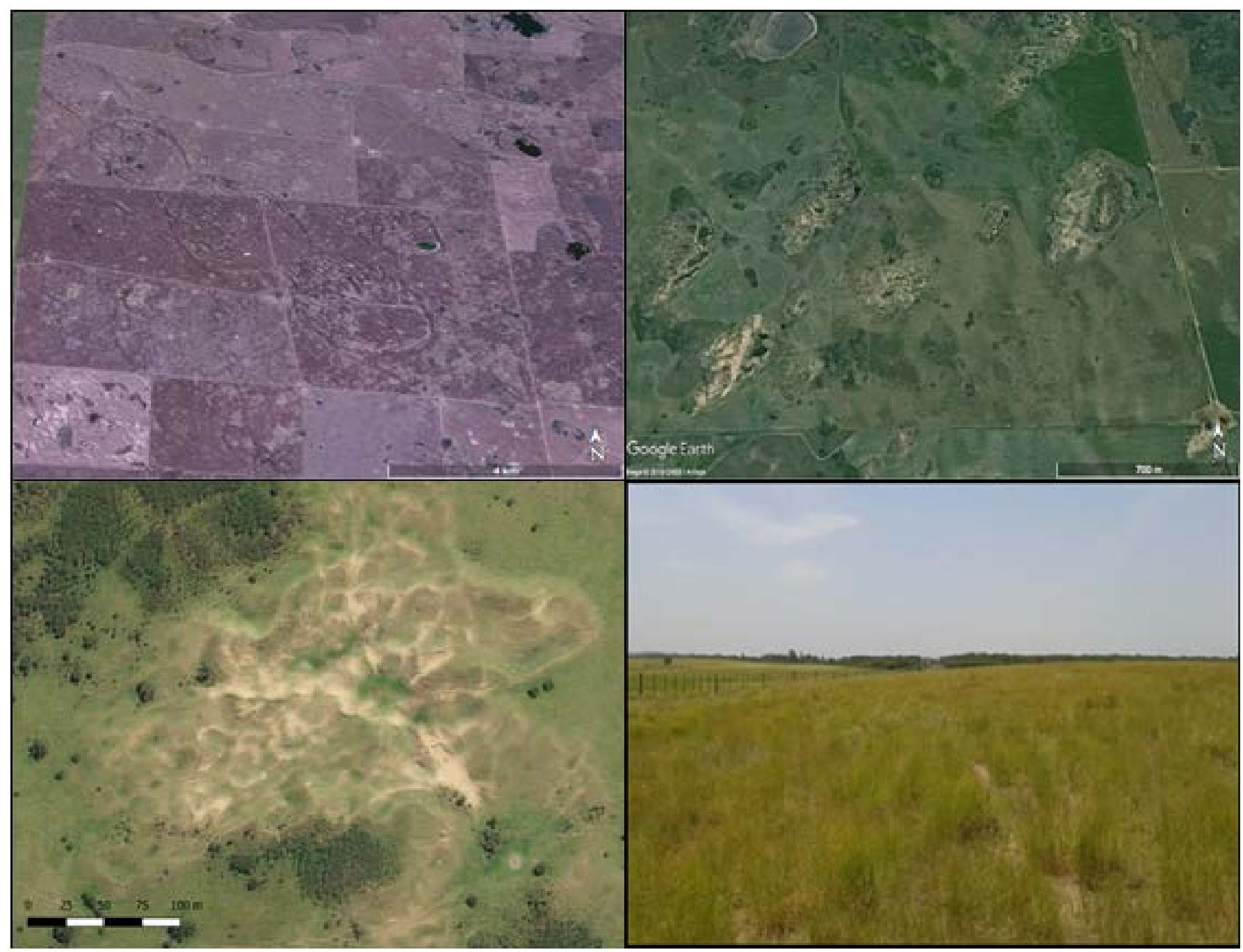

Figura 12 (Superior izquierda). Cadenas de dunas en cadena fijadas de dirección SSE-NNO al oeste de Buena Esperanza, San Luis (Google Earth Pro, Digital Globe, 2018). Figura 13(Superior derecha). Dunas disipadas de dirección SSE-NNO al oeste de Villa Huidobro, a las que se le sobre imponen dunas más recientes de dirección NNE-SSO (Google Earth Pro, Digital Globe, 2018). Figura 14 (Inferior izquierda). Dunas disipadas y fijadas casi en su totalidad por pastizales y monte nativo al norte de Villa Huidobro. Figura 15 (Inferior derecha). Cresta de duna fijada pastizales en un establecimiento al norte de Villa Huidobro. 


\section{Focos de erosión}

En lo que respecta al segundo indicador seleccionado, la visualización de nuevos focos de erosión (Figura 16), representados por superficies desprovistas de cobertura, con material filtrado por el viento y expuesto en lotes agrícolas que no expresan un cambio de uso de la tierra atendiendo la ocurrencia de estos procesos, sustenta lo destacado por Casas (2001), quien menciona que la erosión eólica se ha ido reduciendo de manera visible en la mayor parte de la región Pampeana, excepto en el sur de Córdoba, este de San Luis y sur de la provincia de Buenos Aires (partidos de Villarino y Patagones).

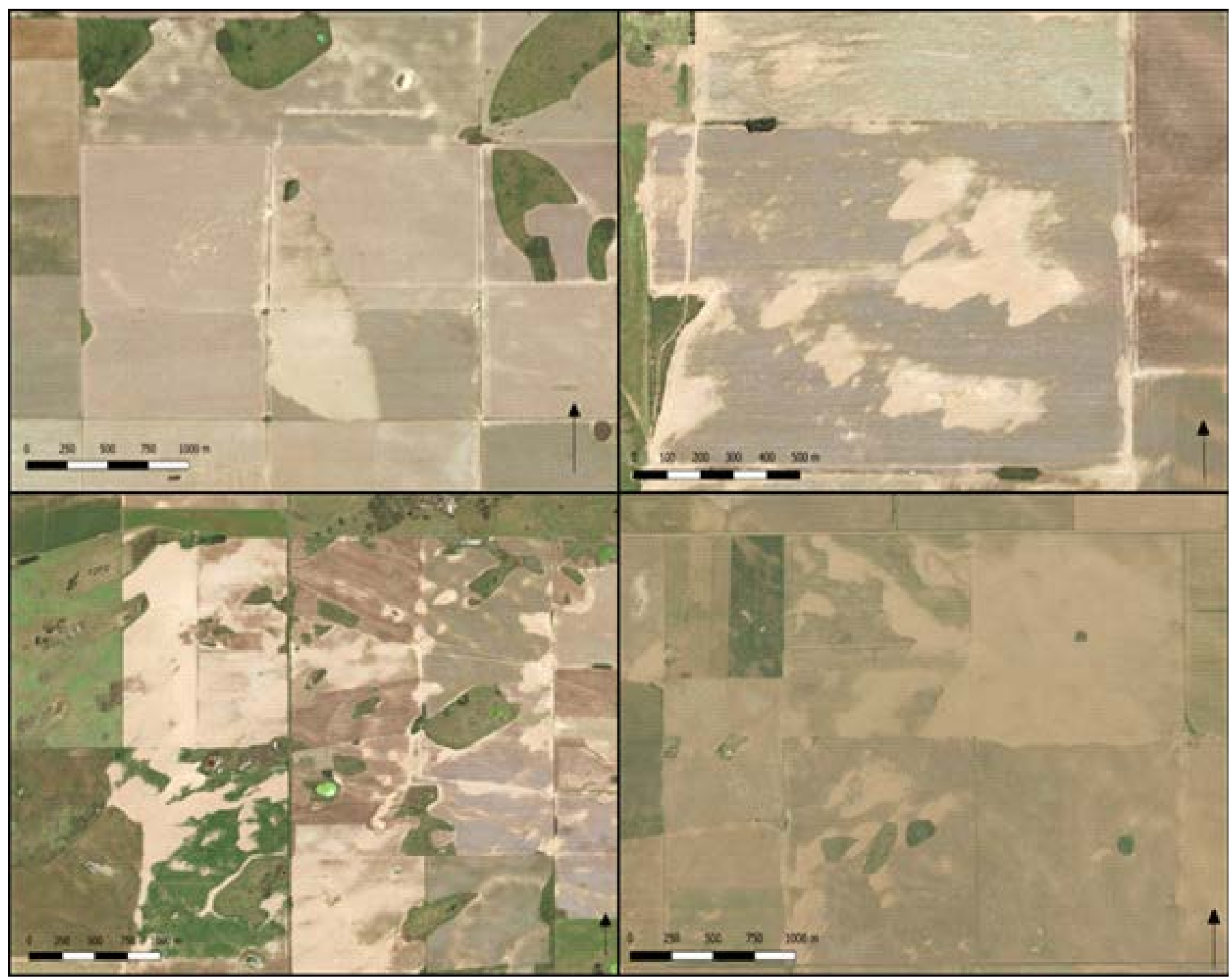

Figura 16. Focos de erosión eólica en campos agrícolas (Imágenes de Bing TM Maps platform, Bing Satellite, 2018). 


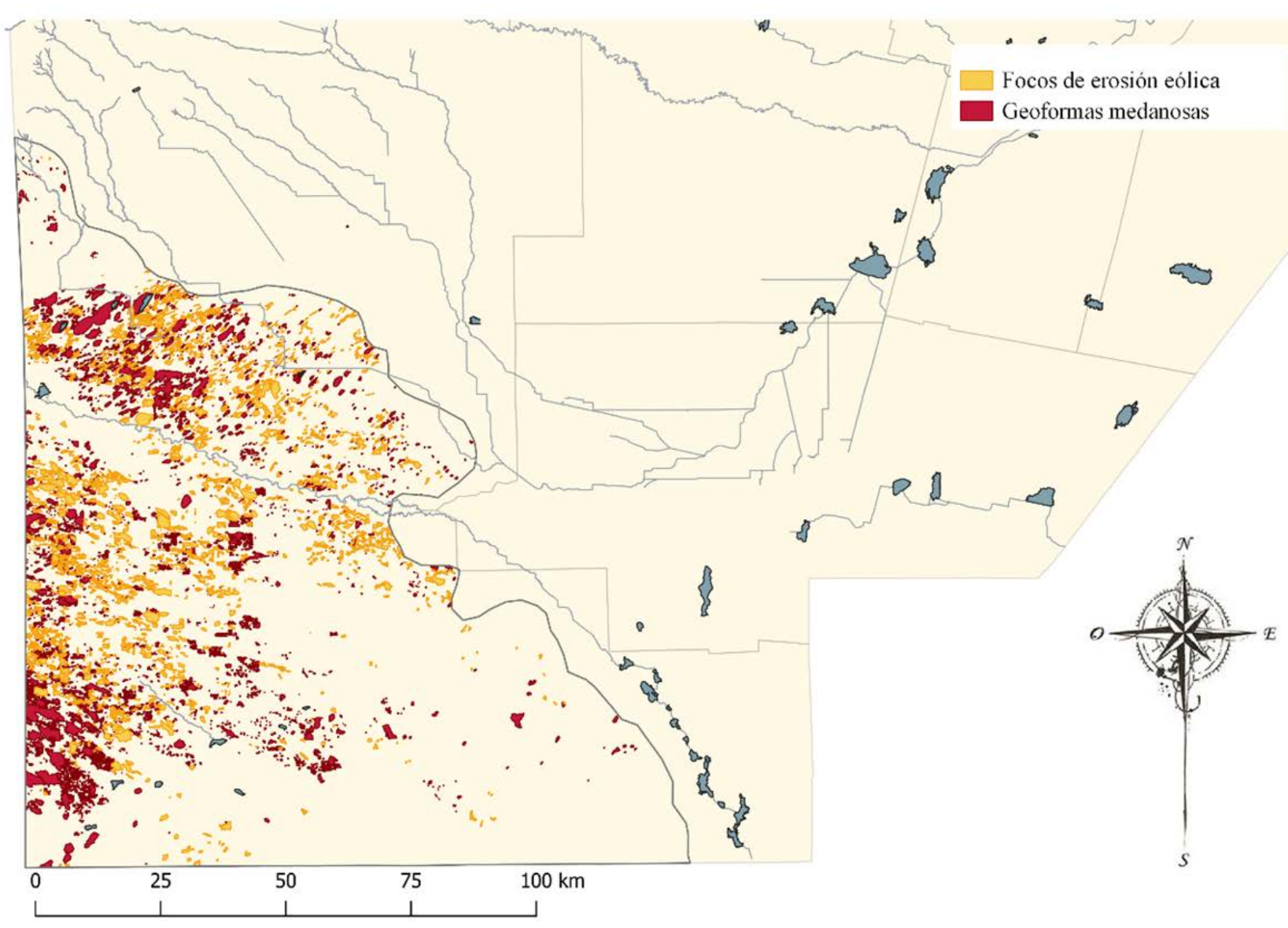

Figura 17. Nuevos focos de erosión eólica activos en la Pampa Medanosa Cordobesa. Localizados principalmente sobre el norte y oeste de la región en los sectores donde se concentran los médanos, y desarrollados en áreas que actualmente pertenecen a sistemas de producción con agricultura.

Se digitalizaron en total 66.448 hectáreas de focos de erosión eólica (Figura 17). Lo que representa un $4,75 \%$ del total de la superficie de la región. Se los observó en tierras bajo uso antrópico, en su mayoría tierras agrícolas, aunque también estuvieron presentes en tierras ganaderas hacia el sur del río Quinto. En vista de que se los encontró asociados a actividades antrópicas, se constituyen en un indicador del inicio de procesos de desertificación (Figura 18). Se encontraron focos en diferentes grados de evolución, desde materiales claros disperso en superficie, hasta montículos de gran tamaño adquiriendo formas de médanos incipientes, pasando por materiales arenosos dispersos y movilizados.

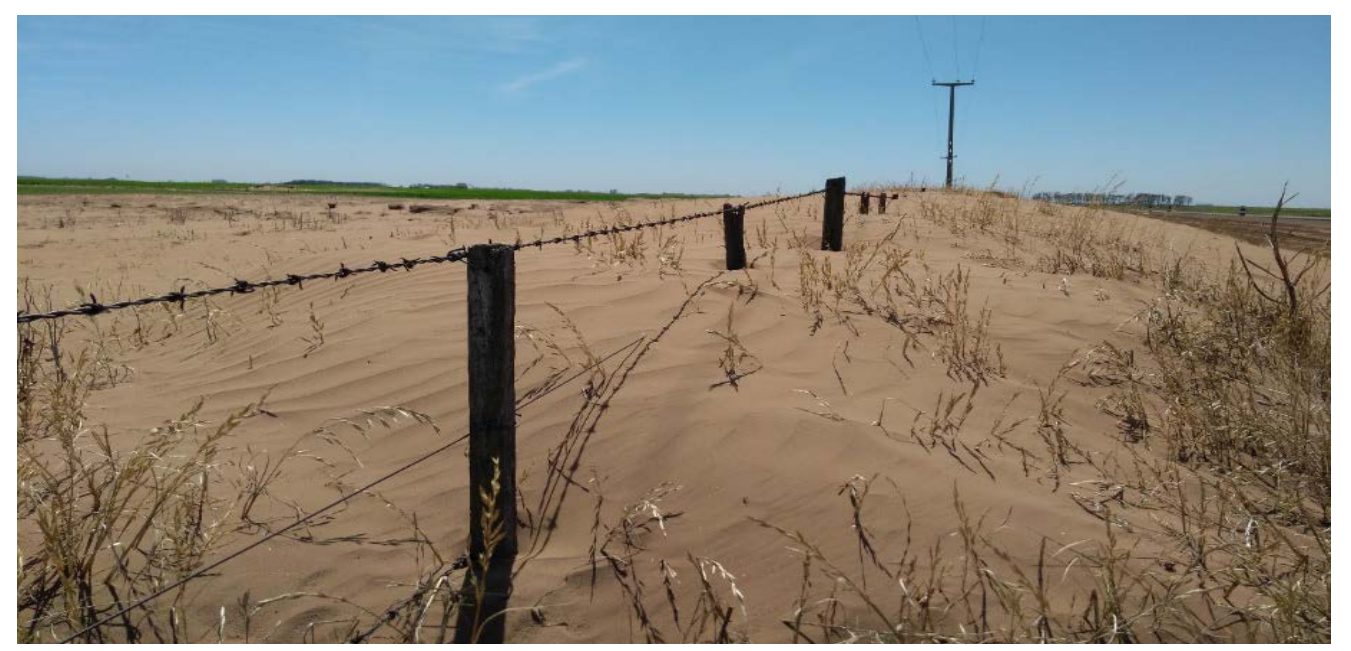

Figura 18. Campo agrícola sembrado con cultivo de maní, en el que se observan enormes deposiciones recientes de arenas cubriendo el alambrado en dirección NE-SO. La fotografía se tomó en la campaña 2017/18, en un establecimiento ubicado sobre la Ruta Nacional $\mathrm{N}^{\circ} 7$. 


\section{Conclusiones}

La superficie total cartografiada correspondiente a geoformas medanosas en la Pampa Medanosa Cordobesa permitió identificar sectores de dunas de génesis holocena y de megadunas más antiguas. En total suman $73.671,6$ hectáreas que indican que un $5 \%$ de la superficie total de la región son ambientes que requieren controles, regulaciones y restricciones para la protección/conservación, atendiendo su fraccionamiento por el uso agrícola y la evidente deforestación en el corredor biogeográfico del Caldenal.

Se digitalizaron además 66.448 hectáreas de focos de erosión eólica, confirmando que un $4,75 \%$ del total de la superficie de la región presenta reactivación de procesos erosivos de tipo eólicos. Hecho que señala la necesidad de la planificación del uso y manejo de la tierra con una visión a largo plazo, a los fines de rehabilitar las tierras degradadas y evitar el avance hacia la desertificación.

\section{Referencias Bibliográficas}

Abraham, E., \& M. Salomón. (2006). Indicadores y puntos de referencia de la desertificación utilizados en argentina por diversos usuarios. Indicadores de la Desertificación para América del Sur. IICA BID, 113140.

Becher Quinodóz, F. N. (2014). Implicancias ambientales de las relaciones hidrodinámicas e hidroquímicas entre aguas superficiales y subterráneas en la planicie arenosa del sur de Córdoba. Tesis Doctoral, Universidad Nacional de Río Cuarto, Río Cuarto, Córdoba, Argentina.

Blarasin, M. T., \& M. L. Sánchez. (1987). Secuencia evolutiva de dunas cuaternarias en el sector de la Laguna Oscura. Departamento Río Cuarto, Provincia de Córdoba, República Argentina. X Congreso Geológico Argentino Actas III: 297-300.

Cabido, D., M. R. Cabido, S. M. Garré, J. A. Gorgas, R. A. Miatello, A. C. Ravelo, ... H. Acuña. (2003). Regiones naturales de la provincia de Córdoba. Córdoba, Argentina. : Agencia Córdoba. Dirección de Ambiente.

Cantero, A., M. P. Cantu, J. M. Cisneros, J. J. Cantero, M. Blarasin, A. Degioanni, ... J. De Prada. (1998). Las tierras y aguas del Sur de Córdoba. Propuestas para un manejo sustentable. Universidad Nacional de Rı Cuarto, Cordoba.

Cantú, M. (1992). Provincia de Córdoba. En: M. Iriondo (Ed.), El Holoceno en la Argentina (Vol. 1). Paraná: Editorial CADINQUA.

Cantú, M., \& S. Degiovanni. (1984). Geomorfología de la Región Centro Sur de la Provincia de Córdoba. 9o Congreso Geológico Argentino, San Carlos de Bariloche, Río Negro, Argentina. Actas IV: 76-92.

Carignano, C., D. Kröhling, S. Degiovanni, \& M. Cioccale. (2014). Geomorfología. XIX Congreso Geológico Argentino: Geología y Recursos Naturales de la Provincia de Córdoba, Córdoba, Argentina.

Casas, R. (2001). La conservación de los suelos y la sustentabilidad de los sistemas agrícolas. Disertación en el acto de entrega del premio Antonio Prego.

Casas, R. (2015). La erosión del suelo en Argentina. In R. R. Casas \& G. F. Albarracín (Eds.), El deterioro del suelo y del ambiente en la argentina. (1 ed., Vol. II, pp. 433-452). Ciudad autónoma de Buenos Aires, Buenos Aires, Argentina: Fundación Ciencia, Educación y Cultura. FECIC.

Cisneros, J., A. Degioanni, J. Gonzalez, C. Cholaky, A. Cantero, J. Cantero, \& J. Tassile. (2015). Erosión y degradación de suelos. Provincia de Córdoba. In R. R. Casa \& G. F. Albarracín (Eds.), El deterioro del suelo y el ambiente en la Argentina ( $1^{\circ}$ ed., Vol. II, pp. 87-100). Buenos Aires: FECIC. Fundación para la Educación la Ciencia y la Cultura.

FAO-Unesco. (1975). Metodología provisional para la evaluación de la degradación de los suelos. FAO, Roma.

Google Earth Pro. (2018). Digital Globe.

Google Maps. (2018). Google Satellite.

Huaico Malhue, A., M. A. Díaz Romero, \& M. I. Carbajal Espejel. (2018). Evolución de los enfoques en desertificación: una revisión de 170 estudios de casos. Cuadernos geográficos de la Universidad de Granada, 57(2), 53-71.

Instituto de Suelos y Agrotecnia. (1948). La erosión eólica en la región Pampeana y plan para la conservación de los suelos. Buenos Aires, Argentina: Ministerio de Agricultura de la Nación. 
Iriondo, M., \& D. M. Kröhling. (1995). El sistema eólico pampeano. Comunicaciones Museo Provincial de Ciencias Naturales" Florentino Ameghino", 5, 1-68.

Iriondo, M. H. (2010). Geología del Cuaternario de Argentina. Argentina: Editorial Moglia.

Jarsún, B., J. A. Gorgas, E. Zamora, H. A. Bosnero, E. Lovera, A. Ravelo, \& J. Tassile. (2006). Recursos Naturales de la Provincia de Córdoba: Los Suelos. Nivel de Reconocimiento 1:500.000 Córdoba, Argentina: Agencia Córdoba Ambiente DACYT-SEM, Instituto Nacional de Tecnología Agropecuaria EEA Manfredi.

Latrubesse, E. M., \& C. G. Ramonell. (2010). Landforms and chronology in the Pampean sand sea, Argentina. $18^{\circ}$ International Sedimentological Congress, Mendoza, Argentina.

Ley provincial $\mathrm{N}^{\circ}$ 8936. (2001). Ley de la conservación y la prevención de degradación de los suelos: Publicada en el Boletín oficial núm.136. 23 de julio de 2001. Secretaría de Agricultura y Ganadería de la provincia de Córdoba. Córdoba, Argentina.

Marelli, H. J. (1996). Provincia de Córdoba. El deterioro del ambiente en la Argentina. (pp. 519): PROSA-FECIC.

Masciángelo, P. 2014. Red hidrogáfica. BID-PID 013/2009-2015. Bases ambientales para el ordenamiento territorial del espacio rural de la provincia de Córdoba. En: http://ordenamientoterritorialcba. com/web3/

Microsoft. (2018). BingTM Maps Platform. Bing Satellite.

Naciones Unidas. (2015). Transforming Our World: The 2030 Agenda for Sustainable Development. New York. 2015. En: http://bit.ly/TransformAgendaSDG-pdf.

Pérez Pardo, O. (2005). La desertificación en la República Argentina. La situación ambiental argentina. Dirección de Conservación del Suelo y Lucha contra la Desertificación, Secretaría de Ambiente y Desarrollo Sustentable, Ministerio de Salud y Ambiente de la Nación. Buenos Aires, Argentina. En: http:// www.fvsa.org.ar/situacionambiental/uso\%20y\%20 deg\%20del\%20suelo.pdf. 07/10/18.
QGIS Development Team. (2019). QGIS Geographic Information System. Open Source Geospatial Foundation Project. En: https://qgis.org.

Rubio, J. L., \& E. Bochet. (1998). Desertification indicators as diagnosis criteria for desertification risk assessment in Europe. Journal of Arid Environments, 39(2), 113-120.

UNCCD. (1994). United Nations Convention to combat desertification in those countries experiencing serious drought and / or desertification, particularly in Africa. United Nations Environment. Geneva: Interim Secretariat for the Convention to combat desertification.

UNCED. (1992). Report of the United Nations Conference on Environment and Development at Rio de Janeiro, Managing Fragile Ecosystems. Combat Desertification and Drought. Chapter 12. U.N. New York.

Valderrama, J. M. (2017). Los desiertos y la desertificación: Los libros de la catarata.

Zárate, M. A., \& A. Tripaldi. (2012). The aeolian system of central Argentina. Aeolian Research, 3(4), 401-417. 